\title{
Cytogenetic biomarkers of radiation exposure
}

\author{
Rhona M. Anderson
}

Centre for Health Effects of Radiological and Chemical Agents, Institute of Environment, Health and Societies, College of Health and Life Sciences, Brunel University London, Uxbridge, UB8 3PH, UK.

rhona.anderson@brunel.ac.uk

3000 words

Statement of searches:

The keywords 'radiation exposure', 'chromosomal biomarker', 'chromosomal signature', and 'complex chromosome aberrations' were used to search Web of Science and Scopus for peer-reviewed articles. 


\section{Abstract}

Biological monitoring of radiation exposure relies heavily on the quantification of chromosome aberrations such as dicentrics and reciprocal translocations in the peripheral blood lymphocytes of exposed and potentially exposed subjects. The differences in the spatial deposition of energy and the quality of damage initially induced between individual low and high-linear energy transfer (LET) radiation tracks are known to impact dramatically on the type and complexity of chromosome aberration induced. Over the years, researchers have proposed numerous cytogenetic markers and signatures based on these differences with the aim of biologically discriminating exposure to radiation of varying qualities. Complex chromosome aberrations are a broad classification of aberration types that are known to be characteristically induced after low doses of high-LET. The mechanistic basis for complex aberration formation and the potential applicability of these complex aberration products as LET-specific biomarkers are considered.

\section{Keywords}

Radiation exposure, high-LET, chromosomal biomarker, chromosomal signature, complex chromosome aberrations. 


\section{Introduction}

The potential health risks of exposure to ionising radiation can be estimated from individualised biological assessments of dose. Some prior knowledge as to the radiation quality and conditions of exposure are necessary if these estimates are to be robust, as biological effect is influenced by linear energy transfer (LET) and dose-rate in addition to dose. In unknown or mixed dose exposure scenarios this may not always be the case. For instance, uncertainties in estimating cancer risks from the neutron component for A-bomb survivors, the potential for internal radionuclide contamination for nuclear workers and from nuclear fallout and, in assessing risks for medical workers exposed to radioactive isotopes $[1,2]$. Expressed in units of $\mathrm{keV} / \mu \mathrm{m}$, LET specifies the average energy transferred per unit length of the track and correspondingly differentiates sparsely (e.g. $x$-rays, $\gamma$-rays) from densely (e.g. $\alpha$-particles, neutrons) ionising radiations as low and high-LET radiation respectively. Medical radiological workers represent an increasingly large population who are occupationally exposed to varying low doses of high-LET exposures over the course of their working lives, potentially combined with low-LET radiation and chemical clastogens [3]. The risks for adverse health from such low dose chronic exposures however remains a matter of debate. Accordingly, there is a need to identify and monitor those who have been exposed to different qualities (LET) of radiation. This is also relevant for the growing number of patients receiving repeated low dose diagnostic radiation exposures of varying quality.

Current biological monitoring relies heavily on the quantification of chromosome aberrations which are detected using various means in the peripheral blood lymphocytes (PBL) of exposed subjects and include dicentrics, reciprocal translocations, micronuclei and sister chromatic exchanges [4]. Indeed, the induction of simple dicentrics and reciprocal 
translocations by low-LET radiation and their application as bio-dosimeters are very well characterized $[5,6]$. The purpose of this article is to provide a general overview of radiationinduced chromosome aberrations with a focus on the types most commonly seen after exposure to high-LET radiation, to examine potential mechanisms of formation and their applicability as LET-specific biomarkers.

\section{Dicentrics and reciprocal translocations are the 'gold' standard for bio-dosimetry}

lonising radiation is extremely effective in inducing structural chromosome aberrations. The mechanism for induction is not fully understood, but is generally accepted to conform to a model of 'breakage-first' followed by 'reunion' $[7,8]$. According to this model, radiation produces a 'break' that results in the complete severance of the chromosome backbone resulting in 'ends' that are free to move. Based on pair-wise interactions, these 'ends' then have three different fates: 'restitution' to produce a cytologically normal chromosome, 'remain open' and be observed as a broken chromosome or to 'illegitimately re-join' with other broken ends and produce visible structural aberrations. At the time of proposing this model, the structure of DNA and the tertiary organisation of chromatin was not known, yet it remains the most widely held theory of chromosome aberration formation today. DNA double strand breaks (DSB) of varying complexity are an important class of damage induced after exposure to ionising radiation and are considered to be the critical lesion in this process [9-11]. In effect, radiation-induced DSB represent 'break ends' and chromosome exchanges are one consequence of the cell's attempts to repair this damage.

Structural chromosome-type aberrations can be broadly classified into two different groups. The symmetrical (or stable) types and the asymmetrical (or unstable) types, with stability 
being defined as the ability of the rearranged chromosome to proceed through mitosis with no loss (or gain) of chromosome material. Stable structural chromosome aberrations include reciprocal translocations and insertions or inversions that result in monocentric rearranged chromosomes, while unstable aberrations include dicentric chromosomes, fragments and rings (Figure 1). Studies have shown that although the chance of forming a reciprocal translocation is equal to the formation of a dicentric plus acentric fragment [12], there is a bias for the formation of acentric rings (intra-arm event) compared to centric rings (interarm event) [13-16]. In other words, the mechanism of exchange between chromosomes is the same and the distribution of the centromere within the exchange is random, but the proximity of breaks relative to each other will influence their chance of repair [17].

A

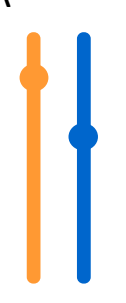

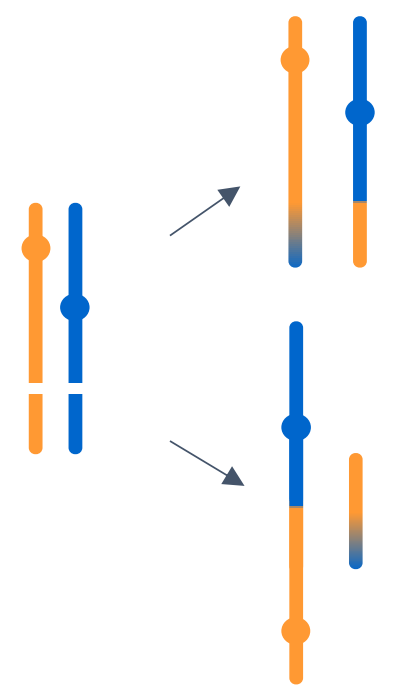

B

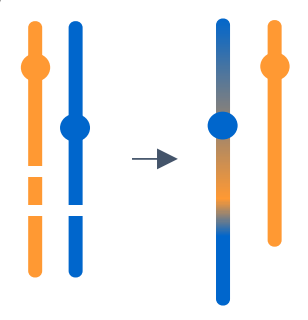

Figure 1: Cartoons depicting structural exchange formation. (A) Two breaks in two chromosomes can 'restitute' to form cytologically normal chromosomes or, incorrectly repair as a symmetrical reciprocal translocation (upper) or asymmetrical dicentric chromosome with associated acentric fragment (lower). (B) Insertions can arise when multiple breaks producing cytologically visible ( $10 \mathrm{Mb})$ sections of chromatin 'rejoin' with one or more than one different chromosomes. 
The aberration of choice for bio-dosimetry has historically been unstable types because of the ease of visualisation using basic solid-staining techniques. Dicentric chromosomes occur at a very low level in un-irradiated persons $(<0.001)[4]$ and increase in a linear [18] or linear-quadratic manner [19] after exposure to high or low-LET radiation respectively. Thus, estimates of whole-body dose can be determined from the PBL dicentric frequency [20]. Due to their unstable nature, the initially-induced dicentric frequency will reduce with time after exposure with a half-life of 2-3 years [21] meaning dicentrics are useful for recent exposures only. In-homogeneity in exposure, rate and different qualities of radiation can also introduce errors in dose estimations.

In situ hybridisation (ISH) was first developed in 1969 by Gall and Pardue [22]. Over the years ISH has been revolutionised through (1) improvements in 'fixation' techniques to maintain the tertiary structure of metaphase chromosomes, (2) the ability to 'sort' individual chromosomes for efficient labelling with multiple, spectrally distinct, fluorophores [23-25] and, (3) the advancement in fluorescence microscopy and image processing software. Fluorescence ISH (FISH) whole chromosome labelling has progressed from 'painting' individual chromosomes the same colour [26], to painting two or three different chromosomes the same or different colours, to painting all the human chromosomes different colours $[27,28]$. Stable reciprocal translocations can now be detected with efficiency after exposures of $\sim 50-100 \mathrm{mGy}$ or greater and correlated with radiation exposure in the distant past [29-32]. Provided these aberrations are not accompanied by additional unstable elements in the damaged cell, then reciprocal translocations will persist with a half-life of $\sim 6$ years for the life-time of the mature PBL, after which time the observed frequency will reflect the frequency of occurrence in precursor haemopoietic stem cells [33]. Thus, FISH-based quantification of reciprocal translocations is currently the 'gold' 
standard for retrospective dosimetry [5]. Reciprocal translocations are not exclusively induced by exposure to radiation however and are accumulated throughout the human lifetime [34-36]. Accordingly, the lowest cumulative dose detectable above this background is strongly influenced by age and inter-individual variation within human populations. Estimates show this to increase linearly at a rate of $1.8 \mathrm{mGy} / \mathrm{year}$ and $15.9 \mathrm{mGy} / \mathrm{year}$ from 20-69 years for acute and chronic exposures respectively [37].

\section{High-LET radiation efficiently induces complex chromosome exchanges}

Although widely observed in solid tumours [38], complex chromosome aberrations were, until the advent of FISH, regarded as rare events after exposure to ionising radiation and not considered relevant in the assessment of radiobiological effects. Defined as any exchange that involves three or more breaks in two or more chromosomes $[39,40]$, complex aberration induction is now established as being strongly dependent on dose in the low-LET range $[41,42]$ but largely independent of dose when the LET is $>100 \mathrm{keV} / \mu \mathrm{m}$. This has been shown for $\alpha$-particles [43-47], neutrons [48-50] and heavy ions [51-53]. Further, as the LET increases from $\sim 100$ - >1000 keV/ $\mu \mathrm{m}$, the frequency and complexity of the complex aberrations induced, also increases [45]. In addition to this, certain rearrangements that had previously been classified as simple reciprocal translocations or dicentrics (maximum of two breaks in two chromosomes) [40] have since been shown to be 'hidden' complex aberrations $[39,54,55]$. As the number of chromosomes capable of being differentially painted by FISH increased to that achieved with multiplex-FISH (M-FISH) or spectral karyotyping (SKY) (24-colour karyotyping), then the effectiveness of detecting additional complexity has also increased $[56,57]$ (Figure 2). 
A

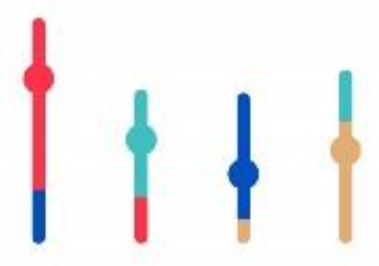

B

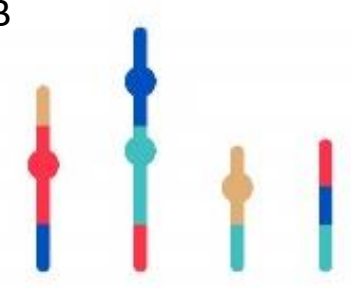

Figure 2: Cartoons depicting $(\mathrm{A})$ stable transmissible complex involving 4 different chromosomes which have incorrectly repaired in a non-reciprocal manner to form 4 rearranged monocentric chromosomes and (B) non-transmissible complex involving 4 different chromosomes which have rearranged in a manner that both forms three visible insertions, dicentric and acetric elements.

Aberration complexity is not just a function of LET but is intimately associated with the qualitative structure of the radiation track [58-60]. Densely ionising radiation such as highLET $\alpha$-particles induce clustered complex DSB along the whole length of the particle track, in contrast to low-LET radiations which produce much more spatially distributed damage [6165]. Furthermore, the range and dimensions of for example, a $5 \mathrm{MeV} \alpha$-particle typically has limited penetrance $(40 \mu \mathrm{m})$ and little maximum radial spread $(\sim 0.1 \mu \mathrm{m})$, with $\sim 90 \%$ of energy deposited within $10 \mathrm{~nm}$ of the particle's path. Consequently, a high-LET $\alpha$-particle is only capable of intersecting with a very small fraction of the total cell volume, which if by chance is intersected, will almost never be intersected by another track even for very high exposures [66]. Yet, $\alpha$-particles and other types of densely ionizing radiation, have been shown in vitro to be very efficient in inducing high frequencies of complex aberrations that commonly involve three, but can be up to seven, different chromosomes $[56,67]$, in addition to intra-chromosomal events [68-70]. 
To explain how such aberrations may be formed, a model was proposed based on theoretical 're-joining' cycles $[12,54,56]$ whereby complex exchanges arise through the sequential linking of smaller, independent exchanges [71] inferring that aberrations of increasing complexity are cumulative products of multiple, localised rearrangements [58, 67]. This implies that aberration complexity also correlates with the number of different chromosome territories intersected by each track, meaning the geometry of the nucleus influences the aberration type induced. Indeed a reduced frequency and a reduced complexity of complex exchanges are observed in ellipsoid cells compared to spherical cells $[72,73]$ with variations depending upon the angle of particle trajectory through ellipsoid cells [74].

Therefore at low dose, LET and track structure dictate the spatial and temporal proximity of initially-induced lesions, on a DNA, chromatin and nucleus-wide basis which, in turn, influences the aberration type or 'pattern' most likely to be resolved in the following metaphase [60].

\section{Chromosome insertions as stable indicators of high-LET radiation}

An important class of complex aberration is the chromosomal insertion (Figures 1-3). Mechanistically, insertions are characteristic of low doses of high- (but not low-) LET radiation due the proximity of lesions induced $[44,45,49,50,57]$. Further, insertions are commonly regarded as stable complex events since they can be defined as the cytologicallyvisible $(>10 \mathrm{Mb})$ product of an interstitial deletion and its subsequent 'insertion' into a different chromosome or chromosome region. Accordingly, insertions have been proposed as stable indicators of past exposure to high-LET radiation $[43,44,49,75]$. Similarly, Brenner 
and colleagues argue that large ( $>6 \mathrm{MB})$ stable intra-chromosomal (inversions/deletions) to be preferentially induced by $\alpha$-particles and neutrons citing their usefulness as long-lived LET biomarkers. However, insertions are now being resolved as being part of much larger, mostly, unstable complex rearrangements when visualised by M-FISH (Figure 2), in keeping with those previously described, meaning the potential transmissibility of these insertions is much lower than previously thought $[43,57]$. This is reflected by the low relative proportion of complex aberrations which are classified as being of the transmissible-type and the low estimated frequency of damaged, but stable cells [76-78]. Accordingly, insertions are characteristic features of both stable and unstable complex aberrations induced after exposure to high-LET radiation.
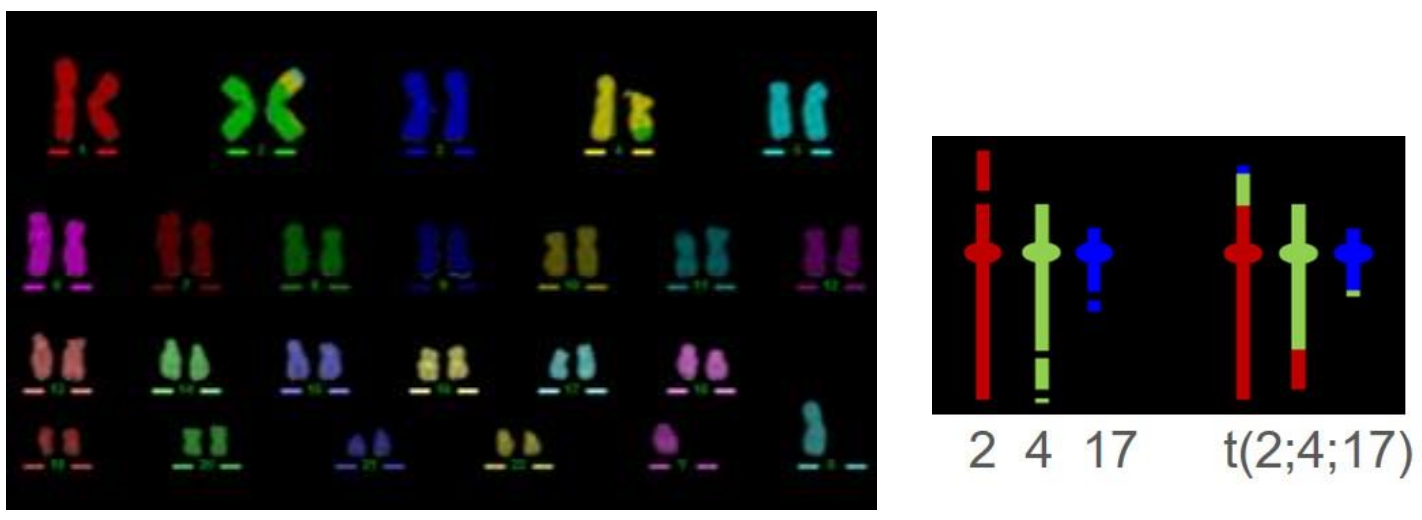

Figure 3: (A) M-FISH karyotype and (B) cartoon showing transmissible complex exchange involving chromosomes 2,4 and 17 . A section of chromosome 4 can be seen as an insertion incorrectly re-joined between the terminal end of chromosome 17 and chromosome 2. 


\section{Signatures of high-LET radiation}

Various researchers have, over the years, proposed candidate 'signatures' of high-LET radiation exposure based on the differences in radiation track structure and the proximity basis of exchange formation as outlined above. The first signature to be proposed was the Fratio [79] which predicts a low ratio of inter-chromosome to intra-chromosome exchanges, on the assumption that high-LET radiation is more likely to result in more intrachromosomal than inter-chromosomal changes, in comparison to low-LET radiation. In a similar vein the $\mathrm{H}$-ratio [15] translates to a bias for the formation of intra-arm intra-changes rather than inter-chromosomal exchanges and, the I-ratio [75] as stable inter-chromosome exchanges rather than stable intra-chromosome exchanges, after exposure to high-LET radiation. The C-ratio (complex: simple exchanges) derives from the arguments already presented in this article.

The potential application of such ratios in vivo is complicated however due to a number of factors including inter-individual differences in the 'background' frequency of interchromosome exchanges within populations [34-36, 80, 81]. Further, although complex aberrations are the predominant exchange type induced in PBL after high-LET radiation, this is not at the exclusion of simple exchanges also being formed [82-84]. A proportion of these simples will be stable reciprocal translocations, both capable of being transmitted to progeny cells $[85,86]$ and, being indistinguishable from those induced by low-LET radiation. 


\section{Complexity per se as an indicator of high-LET radiation}

Complexity is the major cytogenetic feature of high-LET radiation. Differing staining and painting techniques, depending on their resolution, will reveal different elements of the total damage in each cell. The likelihood that even quite subtle (apparently) stable damage (for example an insertion or intra-chromosome exchange) $[69,70]$, is part of a larger complex event that will ultimately be lethal to the cell, is expected to be high, with clear implications for applicability as retrospective markers of exposure.

That said, heavily damaged cells revealed as unstable (and stable) complex aberrations, have been shown to be long lived in vivo many years after exposure. For instance, PBL sampled from retired workers chronically exposed to internalised plutonium ( $\alpha$-particle emitter) (estimated effective doses to the bone marrow in excess of $200 \mathrm{mSv}$ ) contained significantly elevated frequencies of complex chromosome exchanges, of which 20-50\% were classified as transmissible (Figure 3) most likely resulting from dose to the red bone marrow [83]. The remaining non-transmissible (unstable) complexes are thought to represent mature $\mathrm{T}$-cells which remain in their $1^{\text {st }}$ interphase for months or even years after irradiation, until sampled and artificially stimulated to divide in culture. The biological reason for this long-term survival of such heavily damaged PBLs is unclear. However, similar observations, at varying frequencies, have been reported elsewhere including in plutonium workers [87-90], thorotrast patients [85, 91], veterans of nuclear testing [92], A-bomb survivors [93], astronauts and patients receiving carbon therapy [81]. Interestingly, Hande et al [79] found a significant correlation with estimated plutonium dose to the bone marrow (from $\sim 500 \mathrm{mGy}$ ) and yield of complex aberrations suggesting quantification could potentially be used for dose reconstruction. T-cell life-span and immunological status will 
clearly influence the frequency of detection of any chromosome aberration, but for chronic internal exposures, complex aberrations will be induced for the biological and physical lifetime of the radionuclide. As an example, plutonium can remain in the lymph nodes for many years [94] and similar to radium-223, another $\alpha$-particle emitter used in targeted radiotherapy, is deposited on the bone surface meaning both PBL and progenitor cells in the bone marrow may be 'hit' by an $\alpha$-particle.

The bio-distribution of other radionuclides such as iodine-131 will vary and unlike external low-LET radiation, will result in inhomogeneity of dose which complicates assessment [95]. Further, in vivo, cells will be exposed to a spectrum of energies and therefore a spectrum of LETs which will influence the proportion of simple exchanges induced [84]. A linear dose response for the low yield of reciprocal translocations detected in stable cells was seen at $\alpha$ particle doses of greater than 50mGy in vitro [96]. Curwen et al [75] go on to show the validity of using this to estimate $\alpha$-particle dose in a small number of plutonium workers who also exhibited complex aberrations.

Overall therefore, it seems appropriate that complex chromosome aberrations per se should be explored further as indicators of high-LET exposure irrespective of their long-term stability and that their utility as a biomarker of high-LET exposure is used together with reciprocal translocation yields, particularly where internal contamination is known or suspected. 


\section{Conclusion}

The quantification of simple reciprocal translocations or dicentrics for individual assessment of dose is well established for low-LET exposures and is being used to better understand radiobiological effects of low doses of radiation, including that received from diagnostic CT scans and by radiation medical workers [1, 2, 97-100]. For the past twenty years, researchers have sought to build on this and verify cytogenetic markers that discriminate varying qualities (LET) of radiation and through their application, identify individuals exposed to mixed or unknown exposures. All are rooted in a mechanistic understanding of the distinct differences in spatial deposition and of the quality of damage, initially induced between individual low and high-LET radiation tracks and how this relates to the complexity of chromosome aberration resolved using different techniques. The specificity of complex aberration formation after low doses of high-LET radiation coupled with the knowledge they occur rarely in the normal population, promotes complex chromosome aberrations to be essential indicators for this purpose. Their application is tempered however, by their low frequency of occurrence relative to reciprocal translocations in vivo, their unstable nature through cell division and by the requirement for expensive and labour-intensive techniques to fully resolve each damaged cell. Further and larger studies exploring the patterns of complexity and the frequencies of occurrence in different high-LET exposed population groups is necessary therefore before we can fully assess the practical usefulness of complex chromosome aberrations as biomarkers of high-LET exposure.

Structural chromosome aberrations as biomarkers of exposure have been discussed. Chromosome aberrations are also key biomarkers of radiation sensitivity [100] and, are proposed as important indicators of cancer risk [101, 102]. Accordingly, the detailed 
quantification of the entire chromosome aberration burden can provide information on dose and disease risk for each individual (which may alter over time), providing more insight on variations in response and outcome within populations.

\section{References}

[1] Livingston GK, Khvostunov IK, Gregoire E, Barquinero J-F, Shi L, Tashiro S. Cytogenetic effects of radioiodine therapy: a 20-year follow-up study. Radiation and Environmental Biophysics. 2016;55:203-13.

[2] Kopjar N, Garaj-Vrhovac V. Assessment of DNA damage in nuclear medicine personnel comparative study with the alkaline comet assay and the chromosome aberration test. International Journal of Hygiene and Environmental Health. 2005;208:179-91.

[3] UNSCEAR. Exposure of the public and workers from various sources of radiation. In: Publications UN, editor. Sources and Effects of lonising radiation. New York2008.

[4] IAEA. Cytogenetic analysis for radiation dose assessment. Technical Reports Series 405: International Atomic Energy Agency; 2001.

[5] Edwards AA, Lindholm C, Darroudi F, Stephan G, Romm H, Barquincro J, et al. Review of translocations detected by FISH for retrospective biological dosimetry applications. Radiation Protection Dosimetry. 2005;113:396-402.

[6] IAEA. Cytogenetic dosimetry: Applications in preparedness and response to radiation emergencies. In: Agency IAE, editor. Vienna2011.

[7] Sax K. Chromosome aberrations induced by X-rays. Genetics. 1938;23:494-516.

[8] Brown JM, Kovacs MS. Visualization of nonreciprocal chromosome exchanges in irradiated human fibroblasts by fluorescence in situ hybridization. Radiat Res. 1993;136:71-6.

[9] Bender MA, Griggs HG, Bedford JS. Mechanisms of chromosomal aberration production. 3. Chemicals and ionizing radiation. Mutat Res. 1974;23:197-212. 
[10] Natarajan AT, Zwanenburg TS. Mechanisms for chromosomal aberrations in mammalian cells. Mutat Res. 1982;95:1-6.

[11] Cornforth MN, Bedford JS. X-ray--induced breakage and rejoining of human interphase chromosomes. Science. 1983;222:1141-3.

[12] Sachs RK, Chen AM, Simpson PJ, Hlatky LR, Hahnfeldt P, Savage JR. Clustering of radiationproduced breaks along chromosomes: modelling the effects on chromosome aberrations. Int J Radiat Biol. 1999;75:657-72.

[13] Sachs RK, Brenner DJ, Chen AM, Hahnfeldt P, Hlatky LR. Intra-arm and interarm chromosome intrachanges: tools for probing the geometry and dynamics of chromatin. Radiat Res. 1997;148:33040.

[14] Wu H, Durante M, Sachs RK, Yang TC. Centric rings, acentric rings and excess acentric fragments based on a random-walk interphase chromosome model. Int J Radiat Biol. 1997;71:487-96.

[15] Bauchinger M, Schmid E. LET dependence of yield ratios of radiation-induced intra- and interchromosomal aberrations in human lymphocytes. Int J Radiat Biol. 1998;74:17-25.

[16] Natarajan AT, Boei JJ, Vermeulen S, Balajee AS. Frequencies of X-ray induced pericentric inversions and centric rings in human blood lymphocytes detected by FISH using chromosome arm specific DNA libraries. Mutat Res. 1996;372:1-7.

[17] Savage JR, Papworth DG. Comment on the ratio of chromosome-type dicentric interchanges to centric rings for track-clustered compared with random breaks. Radiat Res. 1996;146:236-40. [18] Edwards AA, Lloyd DC, Prosser JS, Finnon P, Moquet JE. Chromosome aberrations induced in human lymphocytes by $8.7 \mathrm{MeV}$ protons and $23.5 \mathrm{MeV}$ helium-3 ions. Int J Radiat Biol Relat Stud Phys Chem Med. 1986;50:137-45.

[19] Lloyd DC, Edwards AA, Prosser JS, Corp MJ. The dose response relationship obtained at constant irradiation times for the induction of chromosome aberrations in human lymphocytes by cobalt- 60 gamma rays. Radiat Environ Biophys. 1984;23:179-89. 
[20] Edwards AA. The use of chromosomal aberrations in human lymphocytes for biological dosimetry. Radiat Res. 1997;148:S39-44.

[21] Buckton KE, Brown WM, Smith PG. Lymphocyte survival in men treated with x-rays for ankylosing spondylitis. Nature. 1967;214:470-3.

[22] Gall JG, Pardue ML. Formation and detection of RNA-DNA hybrid molecules in cytological preparations. Proc Natl Acad Sci U S A. 1969;63:378-83.

[23] Buckle VJ, Kearney L. New methods in cytogenetics. Curr Opin Genet Dev. 1994;4:374-82.

[24] Lichter P. Multicolor FISHing: what's the catch? Trends Genet. 1997;13:475-9.

[25] Le Beau MM. One FISH, two FISH, red FISH, blue FISH. Nat Genet. 1996;12:341-4.

[26] Pinkel D, Straume T, Gray JW. Cytogenetic analysis using quantitative, high-sensitivity, fluorescence hybridization. Proc Natl Acad Sci U S A. 1986;83:2934-8.

[27] Speicher MR, Gwyn Ballard S, Ward DC. Karyotyping human chromosomes by combinatorial multi-fluor FISH. Nat Genet. 1996;12:368-75.

[28] Schrock E, du Manoir S, Veldman T, Schoell B, Wienberg J, Ferguson-Smith MA, et al. Multicolor spectral karyotyping of human chromosomes. Science. 1996;273:494-7.

[29] Lucas JN, Awa A, Straume T, Poggensee M, Kodama Y, Nakano M, et al. Rapid translocation frequency analysis in humans decades after exposure to ionizing radiation. Int J Radiat Biol. 1992;62:53-63.

[30] Knehr S, Bauchinger M. Application of FISH painting for dose reconstruction: Current status and views of the GSF cytogenetics group. Radiat Prot Dosim. 2000;88:15-20.

[31] Bhatti P, Doody MM, Preston DL, Kampa D, Ron E, Weinstock RW, et al. Increased frequency of chromosome translocations associated with diagnostic X-ray examinations. Radiation Research. 2008;170:149-55.

[32] Little MP, Kwon D, Doi K, Simon SL, Preston DL, Doody MM, et al. Association of Chromosome Translocation Rate with Low Dose Occupational Radiation Exposures in US Radiologic Technologists. Radiation Research. 2014;182:1-17. 
[33] Ainsbury E, Moquet J, Rothkamm K, Darroudi F, Vozilova A, Degteva M, et al. What radiation dose does the FISH translocation assay measure in cases of incorporated radionuclides for the Southern Urals populations? Radiation Protection Dosimetry. 2014;159:26-33.

[34] Tucker JD, Lee DA, Ramsey MJ, Briner J, Olsen L, Moore DH, 2nd. On the frequency of chromosome exchanges in a control population measured by chromosome painting. Mutat Res. 1994;313:193-202.

[35] Ramsey MJ, Moore DH, 2nd, Briner JF, Lee DA, Olsen L, Senft JR, et al. The effects of age and lifestyle factors on the accumulation of cytogenetic damage as measured by chromosome painting. Mutat Res. 1995;338:95-106.

[36] Sigurdson A, Ha M, Hauptmann M, Bhatti P, Sram R, Beskid O, et al. International study of factors affecting human chromosome translocations. Mutation Research-Genetic Toxicology and Environmental Mutagenesis. 2008;652:112-21.

[37] Tucker J, Luckinbill L. Estimating the Lowest Detectable Dose of lonizing Radiation by FISH Whole-Chromosome Painting. Radiation Research. 2011;175:631-7.

[38] Rabbitts TH. Chromosomal translocations in human cancer. Nature. 1994;372:143-9.

[39] Savage JR, Simpson PJ. FISH "painting" patterns resulting from complex exchanges. Mutation Research. 1994;312:51-60.

[40] Savage JR, Simpson P. On the scoring of FISH-"painted" chromosome-type exchange aberrations. Mutation Research. 1994;307:345-53.

[41] Simpson PJ, Savage JR. Dose-response curves for simple and complex chromosome aberrations induced by X-rays and detected using fluorescence in situ hybridization. Int J Radiat Biol. 1996;69:429-36.

[42] Loucas BD, Cornforth MN. Complex chromosome exchanges induced by gamma rays in human lymphocytes: an mFISH study. Radiation Research. 2001;155:660-71. 
[43] Anderson RM, Marsden SJ, Wright EG, Kadhim MA, Goodhead DT, Griffin CS. Complex chromosome aberrations in peripheral blood lymphocytes as a potential biomarker of exposure to high-LET alpha-particles. Int J Radiat Biol. 2000;76:31-42.

[44] Griffin CS, Marsden SJ, Stevens DL, Simpson P, Savage JR. Frequencies of complex chromosome exchange aberrations induced by 238Pu alpha-particles and detected by fluorescence in situ hybridization using single chromosome-specific probes. Int J Radiat Biol. 1995;67:431-9.

[45] Testard I, Dutrillaux B, Sabatier L. Chromosomal aberrations induced in human lymphocytes by high-LET irradiation. Int J Radiat Biol. 1997;72:423-33.

[46] Moquet JE, Fernandez JL, Edwards AA, Lloyd DC. Lymphocyte chromosomal aberrations and their complexity induced in vitro by plutonium-239 alpha-particles and detected by FISH. Cell Mol Biol. 2001;47:549-56.

[47] Barquinero JF, Stephan G, Schmid E. Effect of americium-241 alpha-particles on the doseresponse of chromosome aberrations in human lymphocytes analysed by fluorescence in situ hybridization. Int J Radiat Biol. 2004;80:155-64.

[48] Sumption N, Ainsbury L, Goodhead D, Hirama T, Akashi M, Monobe M, et al. High Frequency of Simple and Complex Chromosome Aberrations Detected in the Tokai-mura Survivor four and Five Years after the 1999 Criticality Accident. 2011.

[49] Boei JJ, Vermeulen S, Mullenders LH, Natarajan AT. Impact of radiation quality on the spectrum of induced chromosome exchange aberrations. Int J Radiat Biol. 2001;77:847-57.

[50] Grigorova M, Brand R, Xiao Y, Natarajan AT. Frequencies and types of exchange aberrations induced by X-rays and neutrons in Chinese hamster splenocytes detected by FISH using chromosome-specific DNA libraries. Int J Radiat Biol. 1998;74:297-314.

[51] Wu H, Durante M, Furusawa Y, George K, Kawata T, Cucinotta FA. M-FISH analysis of chromosome aberrations in human fibroblasts exposed to energetic iron ions in vitro. Advances in Space Research. 2003;31:1537-42. 
[52] Lee R, Sommer S, Hartel C, Nasonova E, Durante M, Ritter S. Complex exchanges are responsible for the increased effectiveness of C-ions compared to X-rays at the first post-irradiation mitosis. Mutation Research. 2010;701:52-9.

[53] Durante M, George K, Wu H, Cucinotta FA. Karyotypes of Human Lymphocytes Exposed to HighEnergy Iron lons. Radiat Res. 2002;158:581-90.

[54] Simpson PJ, Papworth DG, Savage JR. X-ray-induced simple, pseudosimple and complex exchanges involving two distinctly painted chromosomes. Int J Radiat Biol. 1999;75:11-8. [55] Simpson PJ, Savage JR. Detecting 'hidden' exchange events within X-ray-induced aberrations using multicolour chromosome paints. Chromosome Res. 1995;3:69-72.

[56] Cornforth MN. Analyzing radiation-induced complex chromosome rearrangements by combinatorial painting. Radiation Research. 2001;155:643-59.

[57] Anderson R, Marsden S, Paice S, Bristow A, Kadhim M, Griffin C, et al. Transmissible and nontransmissible complex chromosome aberrations characterized by three-color and mFISH define a biomarker of exposure to high-LET alpha particles. Radiation Research. 2003;159:40-8.

[58] Anderson RM, Stevens DL, Goodhead DT. M-FISH analysis shows that complex chromosome aberrations induced by alpha -particle tracks are cumulative products of localized rearrangements. Proceedings of the National Academy of Science USA. 2002;99:12167-72.

[59] Durante M, Cella L, Furusawa Y, George K, Gialanella G, Grossi G, et al. The effect of track structure on the induction of chromosomal aberrations in murine cells. Int J Radiat Biol. $1998 ; 73: 253-62$.

[60] Hill M. Track to the future: historical perspective on the importance of radiation track structure and DNA as a radiobiological target. Int J Radiat Biol. 2018;94:759-68.

[61] Lomax ME, Gulston MK, O'Neill P. Chemical aspects of clustered DNA damage induction by ionising radiation. Radiat Prot Dosim. 2002;99:63-8. 
[62] Sutherland BM, Bennett PV, Saparbaev M, Sutherland JC, Laval J. Clustered DNA damages as dosemeters for ionising radiation exposure and biological responses. Radiat Prot Dosim. 2001;97:338.

[63] Goodhead DT. Radiation tracks in biological materials: Initial damage in cells, DNA and associated structures. In: Mendelsohn ML, editor. Genes, Cancer and Radiation Protection. Bethesda, MD.: National Council on Radiation Protection and Measurements.; 1991. p. 25-37. [64] Nikjoo H, Uehara S, Wilson WE, Hoshi M, Goodhead DT. Track structure in radiation biology: theory and applications. Int J Radiat Biol. 1998;73:355-64.

[65] Goodhead DT, Thacker J, Cox R. Effects of Radiations of Different Qualities on Cells - Molecular Mechanisms of Damage and Repair. Int J Radiat Biol. 1993;63:543-56.

[66] Goodhead DT. Track Structure Considerations in Low-Dose and Low-Dose Rate Effects of lonizing-Radiation. Adv Radiat Biol. 1992;16:7-44.

[67] Anderson RM, Papworth DG, Stevens DL, Sumption ND, Goodhead DT. Increased complexity of radiation-induced chromosome aberrations consistent with a mechanism of sequential formation. Cytogenetics and Genome Research. 2006;112:35-44.

[68] Boei JJ, Vermeulen S, Moser J, Mullenders LH, Natarajan AT. Intrachanges as part of complex chromosome-type exchange aberrations. Mutat Res. 2002;504:47-55.

[69] Hande MP, Azizova TV, Geard CR, Burak LE, Mitchell CR, Khokhryakov VF, et al. Past exposure to densely ionizing radiation leaves a unique permanent signature in the genome. American journal of human genetics. 2003;72:1162-70.

[70] Mitchell CR, Azizova TV, Hande MP, Burak LE, Tsakok JM, Khokhryakov VF, et al. Stable intrachromosomal biomarkers of past exposure to densely ionizing radiation in several chromosomes of exposed individuals. Radiat Res. 2004;162:257-63.

[71] Edwards AA, Savage JR. Is there a simple answer to the origin of complex chromosome exchanges? Int J Radiat Biol. 1999;75:19-22. 
[72] Themis M, Garimberti E, Hill MA, Anderson R, M. Reduced chromosome aberration complexity in normal human bronchial epithelial cells exposed to low-LET g-rays and high-LET a-particles. Int J Radiat Biol. 2013;89:66-77.

[73] Foster HA, Estrada-Girona G, Themis M, Garimberti E, Hill MA, Bridger JM, et al. Relative proximity of chromosome territories influences chromosome exchange partners in radiation-induced chromosome rearrangements in primary human bronchial epithelial cells. Mutation Research / Genetic Toxicology Environmental Mutagenesis. 2013;756:66-77.

[74] Durante M, Pignalosa D, Jansen JA, Walboomers XF, Ritter S. Influence of Nuclear Geometry on the Formation of Genetic Rearrangements in Human Cells. Radiation Research. 2010;174:20-6.

[75] Deng W, Morrison DP, Gale KL, Lucas JN. A comparative study on potential cytogenetic fingerprints for radiation LET in human lymphocytes. Int J Radiat Biol. 2000;76:1589-98.

[76] Anderson RM, Marsden SJ, Paice SJ, Bristow AE, Kadhim MA, Griffin CS, et al. Transmissible and Nontransmissible Complex Chromosome Aberrations Characterized by Three-Color and mFISH Define a Biomarker of Exposure to High-LET alpha Particles. Radiation Research. 2003;159:40-8. [77] Duran A, Barquinero JF, Caballin MR, Ribas M, Barrios L. Persistence of Radiation-Induced Chromosome Aberrations in a Long-Term Cell Culture. Radiation Research. 2009;171:425-37. [78] Curwen G, Sotnik N, Cadwell K, Azizova T, Hill M, Tawn E. Chromosome aberrations in workers with exposure to alpha-particle radiation from internal deposits of plutonium: expectations from in vitro studies and comparisons with workers with predominantly external gamma-radiation exposure. Radiation and Environmental Biophysics. 2015;54:195-206.

[79] Brenner DJ, Sachs RK. Chromosomal "fingerprints" of prior exposure to densely ionizing radiation. Radiat Res. 1994;140:134-42.

[80] Sasaki MS. F-value as a chromosomal fingerprint of the quality of radiation. J Radiat Res. 1999;40:165-71.

[81] Durante M, Ando K, Furusawa Y, Obe G, George K, Cucinotta F. Complex chromosomal rearrangements induced in vivo by heavy ions. Cytogenetic and Genome Research. 2004;104:240-4. 
[82] Hande MP, Azizova TV, Burak LE, Khokhryakov VF, Geard CR, Brenner DJ. Complex chromosome aberrations persist in individuals many years after occupational exposure to densely ionizing radiation: an mFISH study. Genes Chromosomes Cancer. 2005;44:1-9.

[83] Anderson RM, Tsepenko VV, Gasteva GN, Molokanov AA, Sevan'kaev AV, Goodhead DT. mFISH Analysis Reveals Complexity of Chromosome Aberrations in Individuals Occupationally Exposed to Internal Plutonium: A Pilot Study to Assess the Relevance of Complex Aberrations as Biomarkers of Exposure to High-LET alpha Particles. Radiat Res. 2005;163:26-35.

[84] Anderson RM, Stevens DL, Sumption ND, Townsend KM, Goodhead DT, Hill MA. Effect of linear energy transfer (LET) on the complexity of alpha-particle-induced chromosome aberrations in human CD34+ cells. Radiat Res. 2007;167:541-50.

[85] Littlefield LG, Travis LB, Sayer AM, Voelz GL, Jensen RH, Boice JD, Jr. Cumulative genetic damage in hematopoietic stem cells in a patient with a 40-year exposure to alpha particles emitted by thorium dioxide. Radiat Res. 1997;148:135-44.

[86] Kraft D, Ritter S, Durante M, Seifried E, Fournier C, Tonn T. Transmission of clonal chromosomal abnormalities in human hematopoietic stem and progenitor cells surviving radiation exposure. Mutat Res-Fundam Mol Mech Mutagen. 2015;777:43-51.

[87] Curwen GB, Sotnik NV, Cadwell KK, Azizova TV, Hill MA, Tawn EJ. Chromosome aberrations in workers with exposure to a-particle radiation from internal deposits of plutonium: expectations from in vitro studies and comparisons with workers with predominantly external g-radiation exposure. Radiation and Environmental Biophysics. 2015.

[88] Sotnik NV, Osovets SV, Scherthan H, Azizova TV. mFISH analysis of chromosome aberrations in workers occupationally exposed to mixed radiation. Radiation and Environmental Biophysics. 2014;53:347-54.

[89] Tawn EJ, Hall JW, Schofield GB. Chromosome studies in plutonium workers. Int J Radiat Biol Relat Stud Phys Chem Med. 1985;47:599-610. 
[90] Kharchenko T, Slozina N, Neronova E, Nikiforov A. Cytogenetic investigation of occupationally irradiated persons a long time after exposure. Appl Radiat Isot. 2000;52:1161-4.

[91] Sasaki MS, Takatsuji T, Ejima Y, Kodama S, Kido C. Chromosome aberration frequency and radiation dose to lymphocytes by alpha-particles from internal deposit of Thorotrast. Radiat Environ Biophys. 1987;26:227-38.

[92] Wahab M, Nickless E, Najar-M'Kacher R, Parmentier C, Podd J, Rowland R. Elevated chromosome translocation frequencies in New Zealand nuclear test veterans. Cytogenetic and Genome Research. 2008;121:79-87.

[93] Awa AA, Neel JV. Cytogenetic "rogue" cells: what is their frequency, origin, and evolutionary significance? Proc Natl Acad Sci U S A. 1986;83:1021-5.

[94] Whitehouse CA, Tawn EJ, Riddell AE. Chromosome aberrations in radiation workers with internal deposits of plutonium. Radiat Res. 1998;150:459-68.

[95] ICRP. Occupational Intakes of Radionuclides: Part 3. Annals of ICRP; 2017.

[96] Curwen G, Tawn E, Cadwell K, Guyatt L, Thompson J, Hill M. mFISH Analysis of Chromosome Aberrations Induced In Vitro by alpha-Particle Radiation: Examination of Dose-Response Relationships. Radiation Research. 2012;178:414-24.

[97] Vellingiri B, Shanmugam S, Subramaniam MD, Balasubramanian B, Meyyazhagan A, Alagamuthu $\mathrm{K}$, et al. Cytogenetic endpoints and Xenobiotic gene polymorphism in lymphocytes of hospital workers chronically exposed to ionizing radiation in Cardiology, Radiology and Orthopedic Laboratories. Ecotoxicology and Environmental Safety. 2014;100:266-74.

[98] Movafagh A, Maleki F, Fadaie S, AzarGashb E. Persistent unstable chromosomal aberrations in lymphocytes of radiotherapy workers after 1(st) mitotic division in Tehran, Iran. Pakistan Journal of Medical Sciences. 2007;23:254-8.

[99] Shi L, Fujioka K, Sakurai-Ozato N, Fukumoto W, Satoh K, Sun JY, et al. Chromosomal Abnormalities in Human Lymphocytes after Computed Tomography Scan Procedure. Radiation Research. 2018;190:424-32. 
[100] Oestreicher U, Endesfelder D, Gomolka M, Kesminiene A, Lang P, Lindholm C, et al. Automated scoring of dicentric chromosomes differentiates increased radiation sensitivity of young children after low dose CT exposure in vitro. Int J Radiat Biol. 2018;94:1017-26.

[101] Bonassi S, Norppa H, Ceppi M, Stromberg U, Vermeulen R, Znaor A, et al. Chromosomal aberration frequency in lymphocytes predicts the risk of cancer: results from a pooled cohort study of 22358 subjects in 11 countries. Carcinogenesis. 2008;29:1178-83.

[102] Fucic A, Znaor A, Strnad M, van der Hel O, Aleksandrov A, Miskov S, et al. Chromosome damage and cancer risk in the workplace: the example of cytogenetic surveillance in Croatia. Toxicology letters. 2007;172:4-11.

\section{Acknowledgements}

I am grateful to Dr Alex Perry and Dr Kai Craenen for their useful comments on this manuscript. 